BMJ

Open

Gastroenterology

\title{
Mortality in coeliac disease: a population-based cohort study from a single centre in Southern Derbyshire, UK
}

\author{
Geoffrey K T Holmes, ${ }^{1}$ Andrew Muirhead ${ }^{2}$
}

To cite: Holmes GKT, Muirhead A. Mortality in coeliac disease: a population-based cohort study from a single centre in Southern Derbyshire, UK. BMJ Open Gastro 2018;5:e000201. doi:10.1136/ bmjgast-2018-000201

Received 19 February 2018 Revised 13 March 2018 Accepted 29 March 2018
Check for updates

${ }^{1}$ Royal Derby Hospital, Derby, UK

${ }^{2}$ Department of Public Health, Derby City Council, Derby, UK

Correspondence to Dr Geoffrey K T Holmes; geoffreyholmes31@gmail.com

\section{ABSTRACT}

Objective With the advent of screening tests, it was hypothesised that milder cases of coeliac disease coming to diagnosis might have reduced risk of mortality. An earlier publication did not support this view. We have reexamined this issue employing a larger number of patients followed for a further 8 years.

Design Patients with coeliac disease from Southern Derbyshire, UK, were followed prospectively from 1978 to 2014 and included those diagnosed by biopsy and serology. Causes of death were ascertained. Standardised mortality ratios were calculated for all deaths, cardiovascular disease, malignancy, accidents and suicides, respiratory and digestive disease. Ratios were calculated for individual causes. Analysis centred on the postdiagnosis period that included follow-up time beginning 2 years from the date of coeliac disease diagnosis to avoid ascertainment bias. Patients were stratified according to date of diagnosis to reflect increasing use of serological methods.

Results All-cause mortality increase was $57 \%$. Mortality in the serology era declined overall. Mortality from cardiovascular disease, specifically, decreased significantly over time. Death from respiratory disease significantly increased in the postdiagnosis period. The standardised mortality ratio for non-Hodgkin's lymphoma was 6.32 , for pneumonia 2.58 , for oesophageal cancer 2.80 and for liver disease 3.10. Survival in those who died after diagnosis increased by three times over the past three decades.

Conclusions Serological testing has impacted on the risk of mortality in coeliac disease. There is an opportunity to improve survival by implementing vaccination programmes for pneumonia and more prompt, aggressive treatments for liver disease.

\section{INTRODUCTION}

In recent years following the introduction of reliable serological tests to detect coeliac disease and using case-finding strategies, we hypothesised that milder cases might be coming to diagnosis and have reduced risk of mortality. To examine this proposition, a study of deaths was undertaken in patients with coeliac disease recruited from Southern
Summary box

What is already known about this subject?

- People with coeliac disease have an increased all-cause mortality compared with the general population.

- There has been an exponential increase in the rate of diagnosis since the 1990s and commencement of serological testing.

- There is an increased risk of mortality from malignancies.

What are the new findings?

- Coeliac patients are at increased risk of death from pneumonia compared with the general population. Mortality from respiratory disease has increased over time. A significant increase in liver disease occurred.

- Mortality from cardiovascular disease has decreased significantly in the postserology era.

- The total all-cause mortality increase is estimated to be $57 \%$ in patients with coeliac disease and $50 \%$ of the overall difference in risk in now attributed to conditions associated with coeliac disease.

- There is evidence that serological testing has impacted on risk of mortality over time.

How might it impact on clinical practice in the foreseeable future?

- Earlier diagnosis by employing screening tests might reduce mortality in coeliac disease

- There is an opportunity to reduce the risk of death by more prompt treatment of chest infection and by increasing vaccination rates for pneumococcus.

- Early diagnosis of liver problems and more aggressive treatment in coeliac disease might reduce deaths.

Derbyshire, UK, until the end of 2006. When results were stratified according to the period of diagnosis (pre-1990, 1990-1999, and 2000 onwards), which corresponded to increasing use of serological tests in the diagnosis of coeliac disease, it was found that risk of mortality had not changed over the years of 
the study. ${ }^{1}$ The aim of the present survey was to re-examine this hypothesis using a larger number of patients coming from the same area, employing similar methodology and followed for a further 8 years to the end of 2014.

\section{METHODS}

\section{Study population}

Patients with a diagnosis of coeliac disease in Southern Derbyshire were followed prospectively from 1978 to the end of 2014. Incident cases were defined as those diagnosed at the beginning of 1978 or later, while those diagnosed between 1958, when the first diagnoses of coeliac disease were first made in Derby and the beginning of 1978, were regarded as prevalent. The date of diagnosis in childhood was taken as the date of clinical diagnosis or small bowel biopsy, which ever was earlier. The diagnosis of coeliac disease was based on characteristic appearances in small bowel biopsies, or the presence of endomysial antibodies or a level of transglutaminase antibodies $>\times 10$ the upper limit of normal for the test. ${ }^{2}$ Transglutaminase antibody was measured with human recombinant transglutaminase as antigen (Celikey; Phadia GmbH, Freiberg, Germany). Patients referred from secondary care centres outside of Southern Derbyshire were excluded from consideration.

Information on deaths was obtained from patient notes, hospital databases and the National Health Service Strategic Tracing Service. Death certificates were obtained from the Office for National Statistics where the primary cause of death was coded to International Statistical Classification of Diseases and Related Health Problems, 10th Revision, Fifth Edition, 2016 (ICD-10).

\section{Statistical analysis}

Population overall and cause-specific mortality rates were obtained using Office for National Statistics population and mortality data for the years 1978-2014, with stratification by 5 -year age category, sex, and calendar year. Using this information and follow-up data from the cohort for each stratum, standardised mortality ratios (SMRs) with 95\% CIs were generated, assuming a Poisson distribution for the observed number of events. Interest lay in deaths resulting from any cause and those that could be attributed to one of the following ICD-10 disease headings: (1) cardiovascular disease (I00-I99), (2) neoplasms (C00-D48), (3) accidents and suicide (S00- Y98), (4) respiratory disease (J00-J99), and (5) digestive disease (K00-K93). Within each of these disease headings chosen where there was a suggestion of an effect from previous research, specific causes of deaths were analysed. Excess mortality attributable to coeliac disease was assessed by calculating the difference between observed and expected mortality rates for deaths where the underlying cause was either non-Hodgkin's lymphoma, pneumonia, or coeliac disease and dividing this by the corresponding difference in mortality rates when considering deaths from any cause.

Two follow-up periods-'peridiagnosis' and 'postdiagnosis'-were considered for analysis when investigating overall mortality and by disease heading. The "peridiagnosis' period was defined as the time within 2 years of the date of diagnosis of coeliac disease. The 'postdiagnosis' period took account of follow-up time beginning 2 years from the coeliac disease diagnosis date. Only time in the postdiagnosis period was considered in subsequent analyses. Patients were stratified according to when they were diagnosed (1) before 1990, (2) between 1990 and 1999, and (3) from 2000 onwards. These intervals were chosen to reflect increasing use of serological tests to detect coeliac disease in Derby. IgA endomysial antibodies were introduced during 1995, and antitissue transglutaminase antibodies were introduced a little later. The formula of Breslow and Day ${ }^{3}$ was used to calculate heterogeneity between the SMRs for each subgroup. Prevalent cases diagnosed before 1978 were excluded from this stratified analysis to ensure better comparability between the groups. All analyses were carried out using Microsoft Excel (Microsoft Office Professional Plus 2010, Microsoft Corporation, Washington, USA).

\section{RESULTS}

By the end of 2014, 2515 patients with coeliac disease were available for study, of whom 1765 were diagnosed by small bowel biopsy and 750 by serological tests alone. The fate of six patients not included in the total could not be determined. Four of these, all females, diagnosed in childhood, could not be traced. Two diagnosed in adult life were lost. Therefore, $99.8 \%$ of cases were accounted for.

By the end of 2014, 2174 patients with at least 2 years of follow-up were available, contributing 23955 person-years of follow-up (table 1). The median duration of follow-up had risen from 6.2 to 9.3 years. The mean age at baseline was older for all patients at 46.1 years, compared with 45.6 years previously, and in those with at least 2 years of

Table 1 Summary of demographic, baseline, and followup characteristics for coeliac disease patients diagnosed in Derby, UK

Patients with at least 2 years All patients of follow-up

\begin{tabular}{lll}
\hline N & 2515 & 2174 \\
No. of deaths & 346 & 284 \\
Person-years of follow-up & 24266 & 23955 \\
$\begin{array}{l}\text { Median duration of follow- } \\
\text { up (IQR) }\end{array}$ & $8.2(4.0-13.7)$ & $9.3(5.6-14.5)$ \\
Mean age at baseline (SD) & $46.1(19.1)$ & $45.5(18.9)$ \\
N (\%), male & $843(33.5)$ & $721(33.2)$ \\
\hline
\end{tabular}

*Deaths and person-years of follow-up occurring after 2 years 


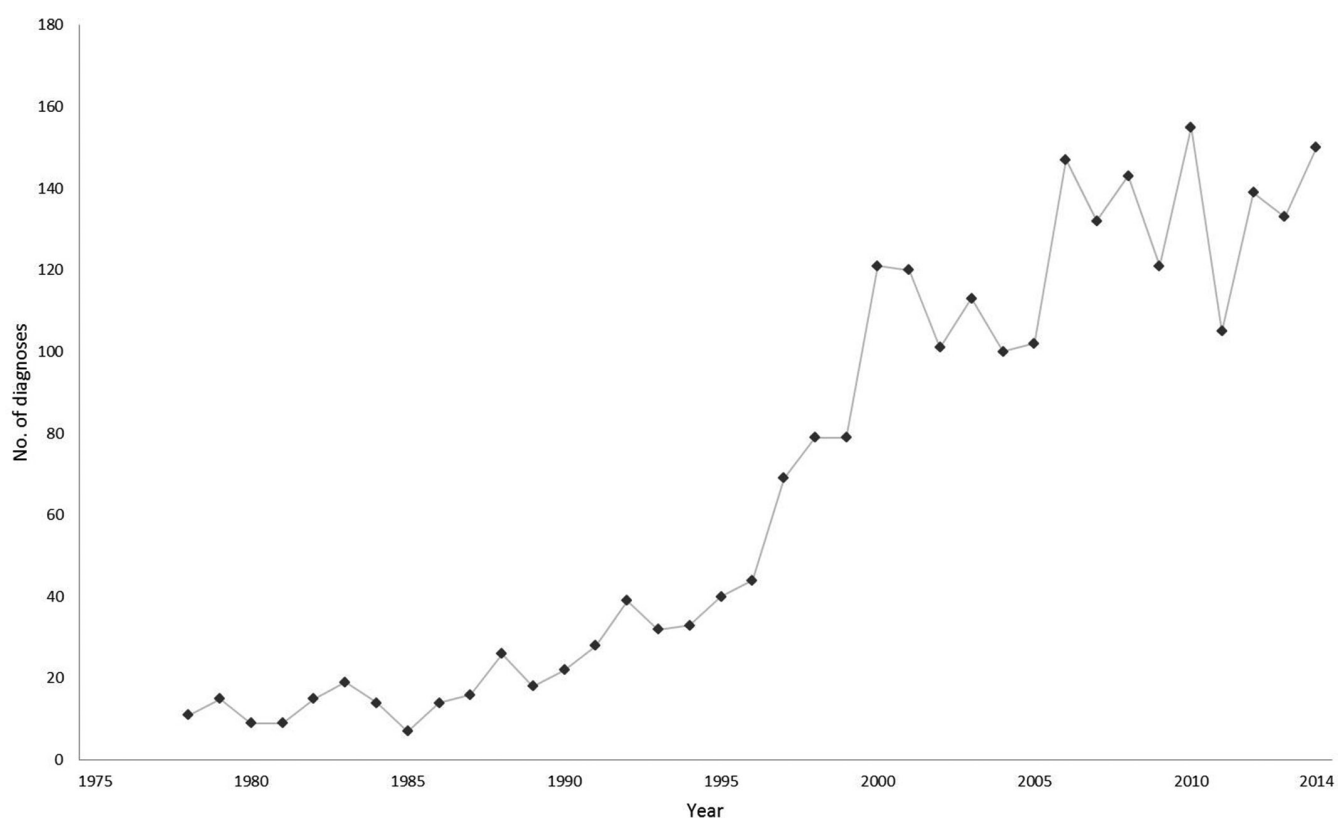

Figure 1 Number of diagnoses of coeliac disease by year in Southern Derbyshire from 1978 to 2014.

follow-up at 45.5 years compared with 44.8 years previously. There were now 284 deaths compared with 142 in the postdiagnosis group. Therefore, considerably more data were available for this new analysis.

There was an exponential year-on-year increase in the number of diagnosed cases of coeliac disease to the end of 2006 (figure 1). Since that time, numbers have plateaued.

\section{Overall mortality risk by diagnosis period}

Table 2 indicates that the SMR for all deaths in the postdiagnosis period is now 1.57 compared with 1.37 previously.
Taking the CIs into account, this is a fractional increase without real significance but could be as much as $77 \%$ more deaths in this population compared with $62 \%$ in the previous study. There were significant increases in deaths for all categories studied except for cardiovascular disease, which fell just short of significant. Of note is the SMR for deaths as a result of respiratory diseases and digestive diseases. While not significant increases on the SMRs were found in the earlier study, the upper CIs suggest that the SMRs could be considerably higher for these two disease areas compared with overall mortality in the general population by as much

\section{Table 2 Observed and expected deaths by disease heading for coeliac disease patients diagnosed in Derby, UK}

\begin{tabular}{|c|c|c|c|}
\hline & Observed & Expected & SMR $(95 \% \mathrm{Cl})$ \\
\hline \multicolumn{4}{|c|}{ Deaths in postdiagnosis period (after 2 years) } \\
\hline All deaths & 284 & 180.4 & $1.57(1.40$ to 1.77$)$ \\
\hline Cardiovascular (I00-199) & 88 & 71.7 & $1.23(0.98$ to 1.51$)$ \\
\hline Malignancy (C00-D48) & 83 & 54.2 & $1.62(1.30$ to 2.00$)$ \\
\hline Accidents/suicide (S00-Y98) & 8 & 2.9 & 2.78 (1.20 to 5.49$)$ \\
\hline Respiratory (J00-J99) & 47 & 20.8 & 2.26 (1.64 to 3.01$)$ \\
\hline Digestive (K00-K93) & 22 & 7.4 & 2.98 (1.86 to 4.51$)$ \\
\hline Other causes & 36 & 23.5 & $1.53(1.07$ to 2.12$)$ \\
\hline \multicolumn{4}{|c|}{ Deaths in peridiagnosis period (within 2 years) } \\
\hline All deaths & 62 & 71.9 & $0.86(0.66$ to 1.11$)$ \\
\hline Cardiovascular (I00-199) & 18 & 30.9 & $0.58(0.34$ to 0.92$)$ \\
\hline Malignancy (C00-D48) & 24 & 19.3 & 1.24 (0.79 to 1.85$)$ \\
\hline Accidents/suicide (S00-Y98) & 0 & 0.6 & 0.00 (0.00 to 6.56$)$ \\
\hline Respiratory (J00-J99) & 4 & 9.9 & $0.40(0.11$ to 1.04$)$ \\
\hline Digestive (K00-K93) & 9 & 2.7 & 3.39 (1.55 to 6.43$)$ \\
\hline Other causes & 7 & 8.5 & 0.82 (0.33 to 1.70$)$ \\
\hline
\end{tabular}

SMR, standardised mortality ratio. 


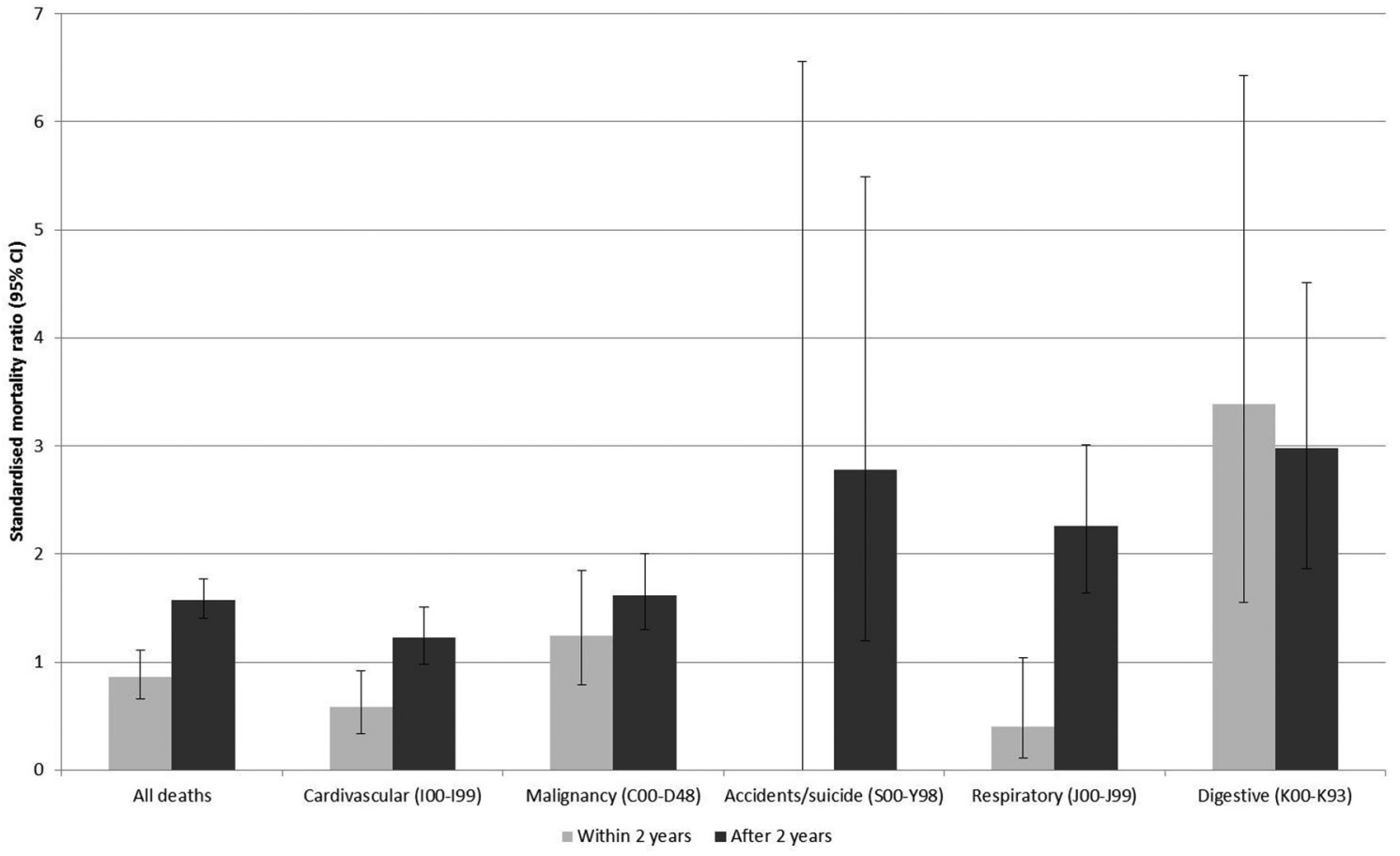

Figure 2 Standardised mortality ratios for patients diagnosed with coeliac disease.

as 4.5 times for digestive cases and 3 times greater for respiratory cases. In the peridiagnosis period, the SMR reduced in all instances apart from cardiovascular disease.

Previously, no significant differences were observed in the risk of deaths occurring in the post or peridiagnosis period in each disease area, apart from accidents and suicide (in which there were no deaths in the peridiagnosis period). Using this more substantial dataset, significant variation is now evident. For cardiovascular and respiratory disease, SMRs in the postdiagnosis period are now significantly greater than in the peridiagnosis period (figure 2). For malignancy, digestive diseases, accidents and suicide, the ratio of mortality within and after 2 years remains insignificant. The SMR for all deaths in this coeliac cohort was significantly higher in the postdiagnosis period.

\section{Risk of mortality by cause of death}

When individual causes of death were analysed for the postdiagnosis period, an increase for non-Hodgkin's lymphoma was observed. (table 3). Breast cancers were non-significantly reduced. No increase or decrease for cancer of the lung was observed. Deaths from pneumonia were significantly increased as well as those from liver disease. A significant increase was also found for oesophageal cancer. No changes for uterine or ovarian tumours occurred.

\section{Mortality stratified by period of diagnosis}

In the previous study, there was no trend towards significant increased or reduced mortality preserological and postserological testing. Now, analysis of all deaths suggests that there has been a decline that just falls short of significant: SMRs of 2.23 (95\% CI 1.83 to 2.70) to end of 1999 and 1.60 (95\% CI 1.32 to 1.92$)$ post-2000. For respiratory diseases, an increase in mortality over the three periods, while still insignificant, is now more marked than in the earlier study-SMRs of 1.34 (to end 1990), 2.50 (19901999), and 2.85 (after 2000) (table 4) —and was the only increase in SMR found. This finding correlates with the heightened indication of deaths attributable to pneumonia and significance of death associated with respiratory disease overall. In other disease areas, risks were greatest during 1990-1999 but reduced post-2000, which follows the same findings as in the earlier study. Mortality from cardiovascular disease has now demonstrated a

Table 3 Observed and expected deaths by individual cause for coeliac disease patients diagnosed in Derby, UK

\begin{tabular}{lccc}
\hline & \multicolumn{3}{l}{ Observed Expected SMR (95\% Cl) } \\
\hline Neoplasms & & 5.2 & $0.19(0.05$ to 1.08$)$ \\
\hline Breast & 1 & 13.0 & $1.16(0.65$ to 1.91$)$ \\
\hline Lung & 15 & 5.6 & $1.42(0.61$ to 2.79$)$ \\
\hline $\begin{array}{l}\text { Colorectal } \\
\text { Non- } \\
\text { Hodgkin's } \\
\text { lymphoma }\end{array}$ & 8 & 1.4 & $6.32(2.89$ to 12.00$)$ \\
$\begin{array}{l}\text { Oesophagus } \\
\text { Respiratory }\end{array}$ & 6 & 2.1 & $2.8(1.03$ to 6.08$)$ \\
\hline $\begin{array}{c}\text { Pneumonia } \\
\text { Digestive }\end{array}$ & 24 & 9.3 & $2.58(1.66$ to 3.85$)$ \\
\hline Liver disease & 8 & 2.6 & $3.10(1.34$ to 6.10$)$ \\
\hline
\end{tabular}

SMR, standardised mortality ratio 


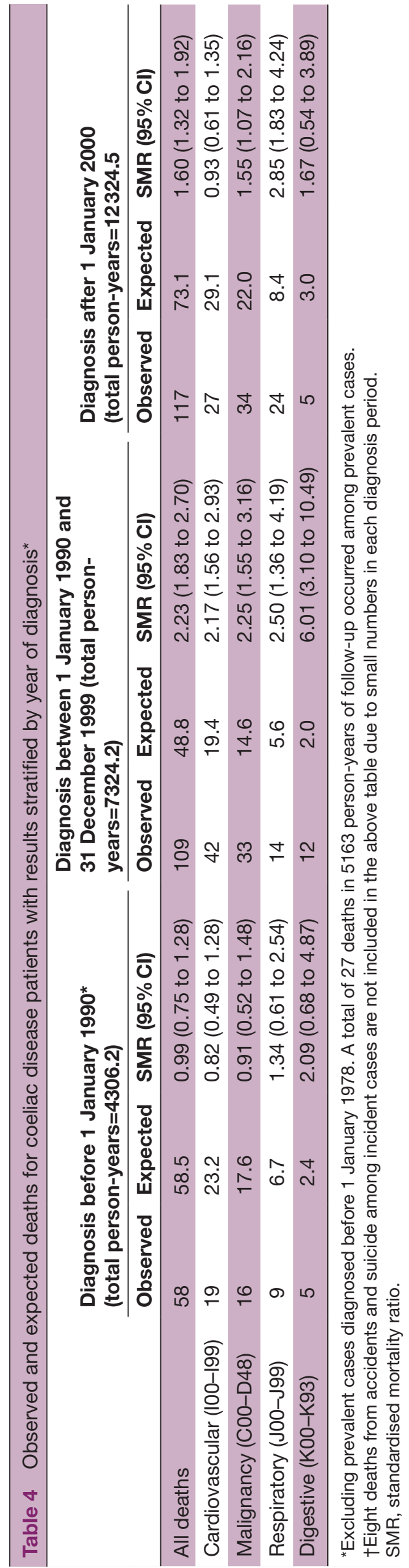

significant reduction from SMR 2.17 (95\% CI 1.56 to 2.93 ) to SMR 0.93 (95\% CI 0.61 to 1.35 ).

\section{Mortality attributable to coeliac disease}

Previously, the overall mortality risk among people with coeliac disease was 14.0 per 1000 person-years compared with 10.2 in the general population. New figures were 11.9 compared with 10.5 , giving an absolute risk difference of 1.4 per 1000 person-years. This has reduced by more than half (table 5). There was no difference in the attributable risk between causes related to and not related to coeliac disease. Previously, $34 \%$ of the overall difference in risk was attributed to coeliac disease deaths while $66 \%$ was not. In the new study it was $50 / 50$. This indicates that the differences in risk attributed to coeliac deaths (non-Hodgkin's lymphoma, pneumonia, liver disease or coeliac disease) is growing.

\section{Survival rates}

The survival rate from the diagnoses of coeliac disease to death has changed over time in the cohort. Those who died in the decade ending 1989 survived on average 3.53 years postdiagnosis. By the end of the 1990s, this time had increased to 5.93 years. For the period 2010-2014, this had increased threefold from three decades earlier to 10.71 years postdiagnosis. The association of diagnosis with death and survival is most apparent in the increase in number diagnosed to 2002 (figure 3), and the same curve being seen in deaths in the years afterwards. This trend in both diagnoses and death has been smoothed using a 3-year moving average. While the number of individuals diagnosed has plateaued since 2006, the number of deaths has continued to rise.

\section{DISCUSSION}

Coeliac disease is being diagnosed in increasing numbers worldwide. ${ }^{4}$ This increase has resulted mainly from greater awareness of coeliac disease and escalating use of reliable serological tests (figure 1). Those diagnosed in the serology era might, because of milder presentations, be at reduced risk of mortality and malignant complications, but our earlier study did not confirm this. ${ }^{1}$ We have re-examined the causes of death in a much larger group of patients with coeliac disease recruited from Southern Derbyshire, UK, and followed for a further 8 years. We have rechecked for changes in mortality that might have occurred through the years with increasing use of serological tests to aid or establish the diagnosis of coeliac disease.

For all deaths for those in the postdiagnosis group, the SMR was 1.57 (95\% CI 1.40 to 1.77). Others have examined excess mortality in coeliac disease. A study from Britain of 4732 cases and 23620 matched controls found a modest increase in mortality with an overall HR of 1.31 (95\% CI 1.13 to 1.51$).^{5}$ An HR of 1.39 (95\% CI 1.33 to 1.45) for deaths was found in an investigation from Sweden. ${ }^{6}$ An examination of 1072 adult patients derived from 11 gastroenterology centres in Italy between 1962 
Table 5 Mortality incidence rate per 1000 person-years stratified by cause of death

\begin{tabular}{|c|c|c|c|}
\hline & All deaths $(n=284)$ & $\begin{array}{l}\text { Deaths attributed to coeliac } \\
\text { deaths* }(n=35)\end{array}$ & $\begin{array}{l}\text { Deaths from causes } \\
\text { not related to coeliac } \\
\text { disease }(n=249)\end{array}$ \\
\hline & Incidence rate $(95 \% \mathrm{Cl})$ & Incidence rate $(95 \% \mathrm{Cl})$ & Incidence rate( $(95 \% \mathrm{Cl})$ \\
\hline Coeliac cohort & 11.9 (10.5 to 13.3$)$ & 1.5 (1.0 to 2.0$)$ & 10.4 (9.1 to 11.8$)$ \\
\hline Attributable risk & $1.4(100 \%)$ & $0.7(50 \%)$ & $0.7(50 \%)$ \\
\hline General population $†$ & 10.5 & 0.8 & 9.7 \\
\hline
\end{tabular}

*Deaths where the underlying cause of death was non-Hodgkin's lymphoma, pneumonia, or coeliac disease.

†Rate standardised by age, sex, and year of follow-up based on the coeliac cohort. Calculation of Cls for the reference group is not appropriate for analysis based on standardised mortality ratios (SMRs).

$\mathrm{Cl}$, exact Poisson $\mathrm{Cl}$.

and 1994 found an overall SMR of 2.0 (95\% CI 1.5 to 2.7). ${ }^{7}$ Those who presented with malabsorption symptoms had increased mortality (SMR $2.595 \%$ CI 1.5 to 2.7), while those who presented with no symptoms and found by screening or mild symptoms had no excess mortality. One explanation is that in more recent years, the increasing use of serological tests to make the diagnosis of coeliac disease has resulted in milder cases being diagnosed who have reduced mortality risk.

Many patients with coeliac disease are undiagnosed, and it is reasonable to assume that these have mild or so-called atypical symptoms that keep them from diagnosis. Several groups have examined whether undiagnosed patients with coeliac disease are at increased risk of mortality or developing non-Hodgkin's lymphoma. In an early small study, increased mortality was not found. ${ }^{8}$ Three European case-control studies of similar design have been published. The risk was threefold for developing non-Hodgkin's lymphoma, but in four of six cases found, the diagnosis of coeliac disease preceded that of non-Hodgkin's lymphoma. ${ }^{9}$ A further study was unable to find an increased risk. ${ }^{10} \mathrm{~A}$ multicentre investigation did find an increased risk of developing non-Hodgkin's lymphoma but only in patients with established coeliac disease, not in those screen detected. ${ }^{11}$ A study from Germany examined mortality in 4570 individuals positive for IgA antitissue transglutaminase antibodies and found an HR of 2.53 for all causes and 3.62 for malignant diseases. ${ }^{12}$ Only one serological test was used, and small bowel biopsies were not performed. Some cases positive for these antibodies, as the authors recognised, might have had heart or liver disease, which could have contributed to the increased mortality. An increased risk of mortality in undiagnosed coeliac disease was not found in other instances ${ }^{13-15}$ neither was the overall risk of developing malignancy increased, although it was for lymphoproliferative conditions. ${ }^{16}$ An American study using stored blood showed excess mortality in undiagnosed

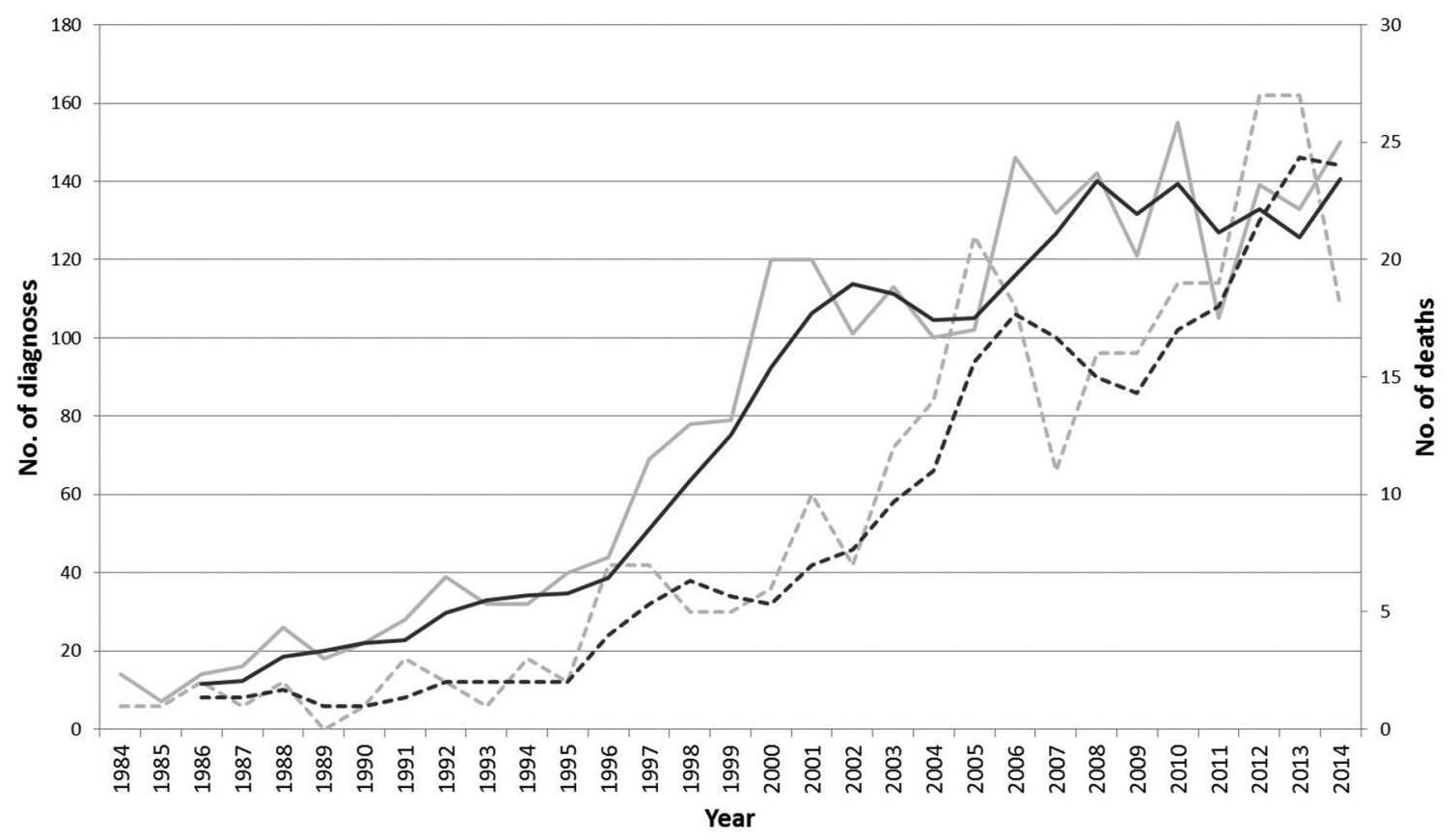

Diagnoses ----Deaths _ 3 per. Mov. Avg. (Diagnoses) - - - 3 per. Mov. Avg. (Deaths)

Figure 3 Trend in diagnosis of coeliac disease and association with mortality. 
coeliac disease with an HR of $3.9(95 \%$ CI 2.0 to 7.5$) .{ }^{17}$ The number of subjects with coeliac disease was small at 14 , but there was a long follow-up time of 45 years, and the excess mortality was only seen after about 15 years of follow-up. This overview indicates that undiagnosed patients with coeliac disease with few exceptions are not at increased risk of mortality.

In the postdiagnosis period of the present study, there were significant increases in deaths from all categories of diseases except for cardiovascular, which just fell short. Cardiovascular disease was the most common cause of death and in each of the whole series and in the postdiagnosis period accounted for $31 \%$. Of 10032 patients with coeliac disease, using the data from the Swedish In-Patients Registry, it was found that $39 \%$ of all deaths were due to cardiovascular disease. ${ }^{18}$ In the same series, $50 \%$ (SMR 95\% CI 1.3 to 1.8) had increased mortality for ischaemic heart disease and 40\% (SMR $1.495 \%$ CI 1.1 to 1.9) increased deaths from cerebrovascular disease in comparison with the Swedish general population. Cardiovascular mortality in the presence of villous atrophy within the Swedish In-Patient Registry coeliac cohort was increased by $19 \%$ (HR $1.1995 \%$ CI 1.11 to 1.28) compared with the population. ${ }^{6}$ Cardiovascular mortality rates were similar in serology-positive undetected coeliac disease and serology-negative controls in American and British population screening studies. ${ }^{14}{ }^{15}$ In a British population-based cohort, no differences were observed in the risk of neither myocardial infarction nor stroke in those with treated coeliac disease in comparison with the general population. ${ }^{19}$ Differences in vascular mortality may be due to differences in smoking patterns and socioeconomic exposures between countries, and the gluten-free diet may alter cardiovascular risk factors. ${ }^{19}$ In our study, mortality from cardiovascular disease has shown a significant decline in the postserological era, which appears to be a new finding and reflects the observation that overall cardiovascular deaths have decreased in recent years. ${ }^{2021}$

The second most common cause of death was malignancy, and overall deaths from this were increased by $62 \%$. An elevated cancer risk was found in a Swedish study of 11019 patients with coeliac disease but $73 \%$ were children at diagnosis (standardised incidence ratio $1.3,95 \%$ CI 1.2 to 1.5$){ }^{22}$ A British study found a similar risk (HR 1.29, 95\% CI 1.06 to 1.55$).{ }^{5}$ In a further Swedish cohort, a $55 \%$ increased risk of dying from cancer was found (HR 1.55, 95\% CI 1.43 to 1.69). ${ }^{6}$ Another study from Britain showed no overall cancer risk in the period at least 2 years after the diagnosis of coeliac disease. ${ }^{23}$ These differences in risk are likely due to the make-up of the various series, the years when the patients were recruited and exclusion of time immediately following the diagnosis of coeliac disease.

When individual neoplasms were considered, an increase in non-Hodgkin's lymphoma was encountered, which has been found by many others. ${ }^{5222425}$ An increase in oesophageal carcinoma occurred, first described many years ago. ${ }^{26}$ Data on coeliac disease and the risk of lung cancer are contradictory with studies showing negative and positive associations. ${ }^{27}$ An investigation from Sweden found a neutral risk ${ }^{27}$ but the effects of confounding factors, particularly smoking habits, could not be fully assessed. In the present study, a neutral association was also found. A reduction in breast cancer has been reported in coeliac disease. ${ }^{28}$ While we also found a reduction, this just failed to reach statistical significance. The risks of breast and lung cancer were decreased but that of colon cancer increased in a study for Finland. ${ }^{29}$

Patients with coeliac disease are prone to develop problems of the respiratory system including pneumonia (SMR 2.9, 95\% CI 2.1 to 3.8). ${ }^{18}$ We have now encountered a significant increase in deaths due to pneumonia in keeping with increasing SMRs for respiratory disease through the years (table 4). An increased risk of pneumococcal sepsis occurs in coeliac disease ${ }^{30}$ so there is an opportunity to reduce the risk of death by increasing vaccination rates for pneumococcus and more prompt treatment of chest infection.

We found a significant increase in deaths due to liver disease, whereas in the previous study, there was no significance. Of eight such deaths, five were due to cirrhosis, which has been commented on by others. ${ }^{18}$ This affords an opportunity to reduce deaths by earlier recognition of hepatic problems and more aggressive treatment.

Since 2006, the number of cases being diagnosed annually has plateaued at about 130-140 cases per year (figure 3). Mortality has continued to rise but is also likely to tail off in the next few years. For those who have died, their life expectancy had increased postdiagnosis over the past three decades from 3.53 years survival on average at the end 1989 to 10.71 years to the end of 2014 . As figure 3 illustrates, the trend in number of deaths is closely correlated to numbers diagnosed, specifically for the peak to 2001 in diagnosed cases that is mirrored again in 2006 for the number of deaths. This study has examined a cohort diagnosed to the end of 2014. We can speculate, based on the current trends, that from 2014 onwards, the number of deaths might equally plateau as newly diagnosed cases have since 2006 .

A strength of this study is that it analysed a substantial number of non-selected patients with coeliac disease attending a single centre, and the outcome for these was complete for $99.8 \%$ of cases. The exclusion of the first 2 years following the diagnosis of coeliac was designed to minimise ascertainment bias in the analysis. Patients diagnosed by serological tests alone using criteria previously validated $^{2}$ and more recently updated ${ }^{31}$ were included. To have ignored these would have removed some $30 \%$ of cases, which would have distorted the results. We can speculate that including serologically diagnosed cases has impacted on the risk of mortality in the cohort as a whole. The SMR for deaths after 1 January 2000 has fallen to 1.60 (95\% CI 1.32 to 1.92 ) from SMR 2.23 (95\% CI 1.83 to 2.70) between 1 January 1990 and 31 December 1999. This is marginally insignificant. Over time, the mortality incidence rate has also fallen from 14.0 per 1000 person 
years in the previous study to 11.9. Since the introduction of serological tests, for those known to have died, survival postdiagnosis had increased from 5.9 to 10.7 years. Further analysis will be required to explore overall survival in this cohort over the last four decades.

Contributors GKTH initiated the cohort, planned the project and collected the data. Both authors processed the data and contributed to writing and production of the final article.

Funding The authors have not declared a specific grant for this research from any funding agency in the public, commercial or not-for-profit sectors.

Competing interests None declared.

Patient consent Not required.

Ethics approval The study was approved by the Confidentiality Advisory Group and the East Midland-Derby Research Ethics Committee.

Provenance and peer review Not commissioned; externally peer reviewed.

Open Access This is an Open Access article distributed in accordance with the Creative Commons Attribution Non Commercial (CC BY-NC 4.0) license, which permits others to distribute, remix, adapt, build upon this work non-commercially, and license their derivative works on different terms, provided the original work is properly cited and the use is non-commercial. See: http://creativecommons.org/ licenses/by-nc/4.0/

C) Article author(s) (or their employer(s) unless otherwise stated in the text of the article) 2018. All rights reserved. No commercial use is permitted unless otherwise expressly granted.

\section{REFERENCES}

1. Grainge MJ, West J, Card TR, et al. Causes of death in people with celiac disease spanning the pre- and post-serology era: a population-based cohort study from Derby, UK. Am J Gastroenterol 2011;106:933-9.

2. Hill PG, Holmes GK. Coeliac disease: a biopsy is not always necessary for diagnosis. Aliment Pharmacol Ther 2008;27:572-7.

3. In: Breslow NE, Day NE, eds. Statistical methods in cancer research. Vol II. The design and analysis of cohort studies (IARC scientific publication no. 82. Lyon, France: International Agency for Research on Cancer, 1987.

4. Holmes GKT, Muirhead A. Epidemiology of coeliac disease in a single centre in Southern Derbyshire 1958-2014. BMJ Open Gastroenterol 2017:4:e000137.

5. West J, Logan RF, Smith CJ, et al. Malignancy and mortality in people with coeliac disease: population based cohort study. BMJ 2004;329:716-9.

6. Ludvigsson JF, Montgomery SM, Ekbom A, et al. Small-intestinal histopathology and mortality risk in celiac disease. JAMA 2009;302:1171-8

7. Corrao G, Corazza GR, Bagnardi V, et al. Mortality in patients with coeliac disease and their relatives: a cohort study. Lancet 2001:358:356-61.

8. Johnston SD, Watson RG, McMillan SA, et al. Coeliac disease detected by screening is not silent--simply unrecognized. QJM 1998;91:853-60.

9. Catassi C, Fabiani E, Corrao G, et al. Risk of non-Hodgkin lymphoma in celiac disease. JAMA 2002;287:1413-9.
10. Farré C, Domingo-Domenech $\mathrm{E}$, Font $\mathrm{R}$, et al. Celiac disease and lymphoma risk: a multicentric case--control study in Spain. Dig Dis Sci 2004;49:408-12.

11. Mearin ML, Catassi C, Brousse N, et al. European multi-centre study on coeliac disease and non-Hodgkin lymphoma. Eur J Gastroenterol Hepatol 2006;18:187-94.

12. Metzger $\mathrm{MH}$, Heier M, Mäki M, et al. Mortality excess in individuals with elevated IgA anti-transglutaminase antibodies: the KORA MONICA Augsburg cohort study 1989-1998. Eur J Epidemiol 2006;21:359-65.

13. Lohi S, Mäki M, Rissanen $\mathrm{H}$, et al. Prognosis of unrecognized coeliac disease as regards mortality: a population-based cohort study. Ann Med 2009;41:508-15.

14. Godfrey JD, Brantner TL, Brinjikji W, et al. Morbidity and mortality among older individuals with undiagnosed celiac disease. Gastroenterology 2010;139:763-9.

15. Canavan C, Logan RF, Khaw KT, et al. No difference in mortality in undetected coeliac disease compared with the general population: a UK cohort study. Aliment Pharmacol Ther 2011;34:1012-9.

16. Lohi S, Mäki M, Montonen J, et al. Malignancies in cases with screening-identified evidence of coeliac disease: a long-term population-based cohort study. Gut 2009;58:643-7.

17. Rubio-Tapia A, Kyle RA, Kaplan EL, et al. Increased prevalence and mortality in undiagnosed celiac disease. Gastroenterology 2009;137:88-93

18. Peters U, Askling J, Gridley G, et al. Causes of death in patients with celiac disease in a population-based Swedish cohort. Arch Intern Med 2003;163:1566-72.

19. West J, Logan RF, Card TR, et al. Risk of vascular disease in adults with diagnosed coeliac disease: a population-based study. Aliment Pharmacol Ther 2004:20:73-9.

20. van der Wall EE. Mortality decrease from cardiovascular disease in Europe: 50 \% in 30 years!. Neth Heart J 2013;21:425-6.

21. Nichols M, Townsend N, Scarborough P, et al. Trends in age-specific coronary heart disease mortality in the European Union over three decades: 1980-2009. Eur Heart J 2013;34:3017-27.

22. Askling J, Linet M, Gridley G, et al. Cancer incidence in a populationbased cohort of individuals hospitalized with celiac disease or dermatitis herpetiformis. Gastroenterology 2002;123:1428-35.

23. Card TR, West J, Holmes GK. Risk of malignancy in diagnosed coeliac disease: a 24-year prospective, population-based, cohort study. Aliment Pharmacol Ther 2004;20:769-75.

24. Catassi C, Bearzi I, Holmes GK. Association of celiac disease and intestinal lymphomas and other cancers. Gastroenterology 2005;128(4 Suppl 1):S79-S86.

25. Elfström P, Granath F, Ekström Smedby K, et al. Risk of lymphoproliferative malignancy in relation to small intestinal histopathology among patients with celiac disease. J Natl Cancer Inst 2011;103:436-44.

26. Harris OD, Cooke WT, Thompson $\mathrm{H}$, et al. Malignancy in adult coeliac disease and idiopathic steatorrhoea. Am J Med 1967;42:899-912.

27. Ludvigsson JF, West J, Hubbard R, et al. Neutral risk of lung cancer in adults with celiac disease--nationwide cohort study. Lung Cancer 2012;78:179-84.

28. Ludvigsson JF, West J, Ekbom A, et al. Reduced risk of breast, endometrial and ovarian cancer in women with celiac disease. Int $J$ Cancer 2012:131:E244-50.

29. Ilus T, Kaukinen K, Virta LJ, et al. Incidence of malignancies in diagnosed celiac patients: a population-based estimate. Am J Gastroenterol 2014;109:1471-7.

30. Ludvigsson JF, Olén O, Bell M, et al. Coeliac disease and risk of sepsis. Gut 2008:57:1074-80.

31. Holmes GKT, Forsyth JM, Knowles S, et al. Coeliac disease: further evidence that biopsy is not always necessary for diagnosis. Eur $J$ Gastroenterol Hepatol 2017;29:640-5. 